\title{
SPATIAL RELATIONSHIP OF BURIED-PIPELINE DAMAGE AND SAND-BOILING AREA DUE TO LIQUEFACTION IN KASHIMA REGION
}

\author{
Soji KATO ${ }^{1}$ and Yasuko KUWATA ${ }^{2}$ \\ ${ }^{1}$ Nonmember of JAEE, Graduate Student, Dept. of Civil Engineering, Kobe University, \\ Kobe, Japan, 141t115t@stu.kobe-u.ac.jp \\ ${ }^{2}$ Member of JAEE, Associate Professor, Dept. of Civil Engineering, Kobe University, \\ Kobe, Japan, kuwata@kobe-u.ac.jp
}

\begin{abstract}
The earthquake and associated aftershocks that occurred off the Pacific coast of Tohoku, Japan on March 11, 2011 caused liquefaction over a large area in the mouth of the Tone River. This study aims to establish a spatial relationship between sand-boiling and the damage done to buried pipelines in the zones of concentrated liquefaction-induced damage in the Kashima region. The pipeline repair rate in the sand-boiling area was roughly 10 times as high as that in the liquefaction-induced pipeline-damage concentration zones. As the pipeline within the sand-boiling area enlarges, percentage of damage occurrence increased and its damage occurred more near the boundaries of the sand-boiling area.
\end{abstract}

Key Words: Kashima region, sand boiling, pipeline damage, spatial relationship

\section{INTRODUCTION}

The earthquake and associated aftershocks that occurred off the Pacific coast of Tohoku, Japan on March 11, 2011 caused liquefaction over large areas in the mouth of the Tone River and the Tokyo Bay area in the Kanto region. From reports of the earthquake damage to the water supply and sewer systems, pipelines in these liquefaction areas were found to have been more extensively damaged than those in areas of strong ground motion or tsunami flooding. ${ }^{1), 2)}$

Several studies have been conducted that focused on the relationship between ground strain and pipeline damage in the liquefaction area based on the experiences of earthquake damage in the 1964 Niigata and 1995 Kobe earthquakes. ${ }^{3), 4)}$ In the case of the 2011 Tohoku earthquake, Toita and Yamazaki ${ }^{5}$ showed that the damage to sewer pipelines was greater where the percentage of liquefied area exceeded a certain value based on an analysis of aerial photographs (APs) of the Urayasu region in Chiba Prefecture. Many of these studies attempted to quantify the magnitudes of sand-boiling (hereafter, SB) and ground deformation from APs by using the liquefied area and the ground strain calculated from before-and-after coordinate differences. They then tried to use these magnitudes to establish a relationship with pipeline damage.

Kuwata and Ikejiri' ${ }^{6}$ specified a pipeline-damage concentration zone (hereafter, PDCZ) from the distribution of damage to water pipelines in the Kashima region (Kamisu, Kashima, and Itako Cities in 
Ibaragi Prefecture and Katori City in Chiba Prefecture) after the 2011 Tohoku earthquake. They showed that the damage in these concentration zones was caused by liquefaction. They went on to suggest that, when estimating pipeline damage, it is important to understand the historical patterns of water distribution by using not only current maps but also older ones. Kuwata and Ikejiri ${ }^{6}$ confirmed the occurrence of liquefaction in the damage-concentration zones but were unable to specify the liquefaction location or conduct a detailed analysis of the spatial relationship between liquefaction SB and pipeline damage. Moreover, they did not consider the damage to sewer pipelines.

Separately, Tsukiji et al. ${ }^{7}$ compiled a liquefaction map from the ones reported by the Japanese Geotechnical Society and the Kanto Area Bureau, Ministry of Land, Infrastructure, and Transport. They also incorporated official building-damage data related to liquefaction in Kamisu City, which lies within the PDCZ. They found that approximately six times as many water pipelines had to be repaired in the liquefied area that in the non-liquefied area. In addition, Shoji et al. ${ }^{8}$ found that the sewer-pipeline repair rate in the liquefied area in Kamisu City was 8.8 times that in the non-liquefied area. Moreover, Hashimoto et al. ${ }^{9}$ specified the former gravel mining site from past APs of the Fukashiba and Hiraizumi districts in Kamisu City, and used local measurements to analyze in detail the damage caused to buildings and sewer pipelines by the subsidence.

In this study, we develop the previous study of Kuwata and Ikejiri ${ }^{6}$ that focused on the PDCZs in the Kashima region. The spatial distributions of SB and surface road cracks induced by the liquefaction are specified using APs taken after the earthquake, and we attempt to relate these to the locations of pipeline damage in the SB area. In addition, the pipeline repair rates of water and sewer systems in the SB areas are established. Aerial photography is shown to be an effective means of analyzing pipeline damage from liquefaction-induced SB. Results of this study will be verified comparing with previous studies undertaken in Kamisu City is verified.

\section{SETTING OF PIPELINE-DAMAGE CONCENTRATION ZONE AND CONSTRUCTION OF GIS DATABASE}

\subsection{Setting of pipeline-damage concentration zone}

We outline the PDCZ determined by Kuwata and Ikejiri ${ }^{6}$ in their previous study. This is defined as the various adjacent districts in which the water-pipeline repair rate is more than 0.3 locations $/ \mathrm{km}$ and the pipeline installation density is more than $10 \mathrm{~km} / \mathrm{km}^{2}$. Under these conditions, seven zones were extracted, all of which are limited to areas of $1-2 \mathrm{~km}^{2}$ and were reported from site investigations as having experienced liquefaction-induced SB. The liquefaction seems to be related to the concentration of damage to the pipelines. By comparing current and old topographical maps, the subsurface ground in the PDCZ was found to be filled ground that had previously been either a river, a polder, or a sand mine. In other words, we are dealing with artificially modified ground.

The four zones (zone A, Horiwari district; zone B, Fukajiba district; zone C, Shitte district; zone D, Hirai district) shown in Figure 1 are targeted because of the availability of APs of the seven zones in this study. The target zones are the southern part of Kashima City and the northern part of Kamisu City. The damage locations and the water-supply pipelines are also shown in Figure 1; damage locations outside the PDCZs are omitted from the targets in this study.

\subsection{Extraction of sand-boiling traces}

The geographic information system (GIS) database was compiled by extracting SB area and road cracking in the PDCZs from APs ${ }^{10)}$ taken on April 1 and 2, 2011 at a resolution of $25 \mathrm{~cm} /$ pixel. These regions were covered by polygons using the authors' subjective judgments. The criteria for a SB area on a road were determined as an obviously white part due to bright boiling sand, a black part due to there being more moisture than on other parts of the road surface, or a part where a SB hole could be confirmed. The criterion for a road crack was taken to be a straight band crossing the road, which was covered by gravel to make the gap flat excluding the shadow of electricity poles. A straight diagonal 


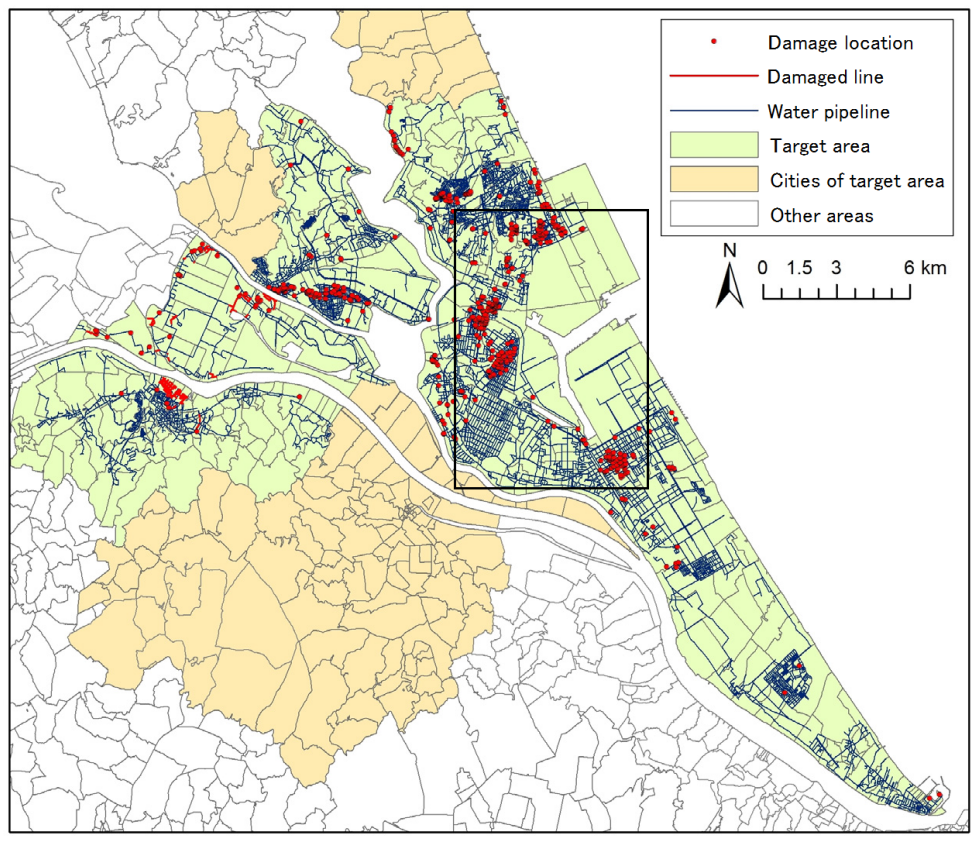

(a) Large map of Kashima region ${ }^{6}$

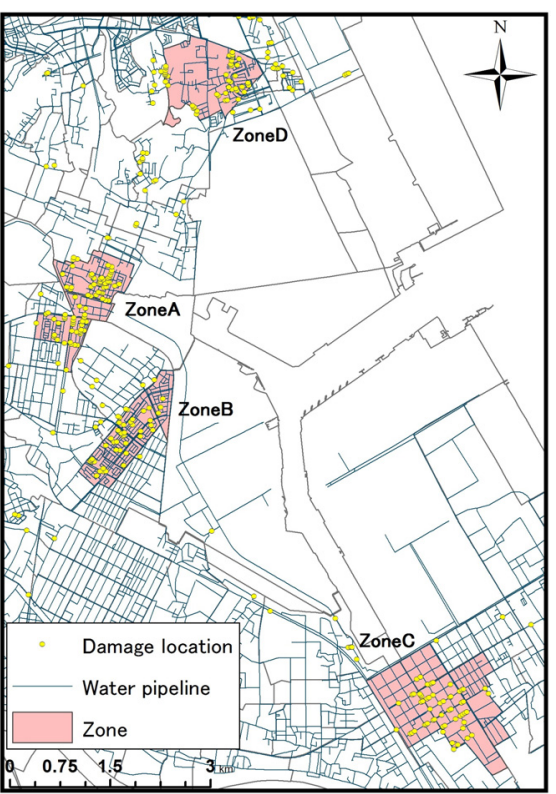

(b) Four concentration-zones

Fig. 1 Pipeline-damage concentration zones (PDCZs)

band was also judged to be a road-crossing crack in this study, but we judged there to be no cracks running in the direction of the roadway. In such circumstances, the crack would be judged as not only a crack but also a SB area. Figure 2 shows examples of placing SB and road-crack polygons, and of marking the pipeline within the SB area by the intersecting features.

Because this study focuses on clarifying the relationship between SB areas and damage locations, only SB and cracks on roads were targeted in developing the database map. Moreover, the Google Earth satellite images taken the day after the earthquake was compared for verification despite its inferior resolution; the APs that we used were taken three weeks after the earthquake, during which time the SB could have already been cleared up. In fact, there were no major differences between the $\mathrm{SB}$ areas in the APs and the satellite image. For extracting regions of road cracking, the three-week-old APs proved more useful than the satellite image because any road repairs were made clear.

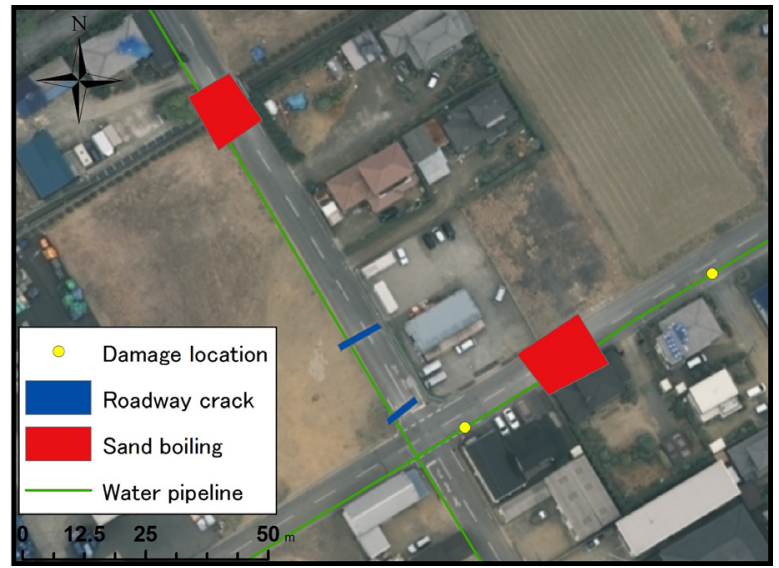

(a) Polygons before intersecting

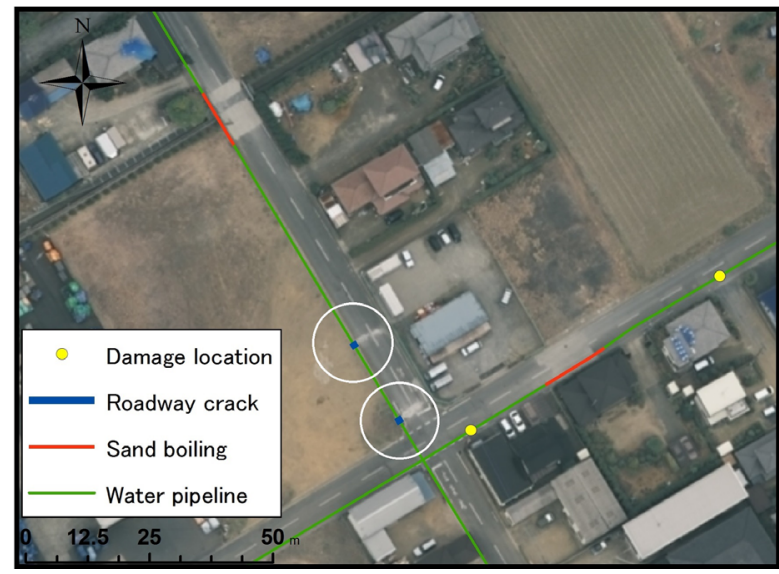

(b) Liquefaction pipeline after intersecting

Fig. 2 Example of extracting pipeline affected by liquefaction 


\subsection{Construction of pipeline database}

Databases of water and sewer pipelines in the PDCZs were used in this study. The water-pipeline database was compiled by using a scanner to digitize a paper map of the pipeline and damage locations, and by modifying the roadway polyline data of the Geographical Survey Institute overlying the scanned map on the GIS. The water pipelines in Kashima City and Kamisu City have been laid widely and densely, and are almost congruent with the roads. In contrast, the sewer-pipeline database covers only Kamisu City and industrial districts nos. 4-6 in Kashima City. The definition of damage to a sewer pipeline is based not on repair points, as with water pipelines, but on malfunctioning lines. The sewer-pipeline system does not extend over as large an area as that covered by the water-pipeline network; the analysis of sewer pipelines in zone A deals with only its southern part.

Figure 3 shows the water pipelines and the liquefaction-induced SB area, road cracks, and damage locations in zones A-D; Figure 4 shows the same for sewer pipelines. Pipeline damage is seen to be concentrated near ground deformation due to SB and road cracks in each zone. The length of pipeline affected by SB is relatively short in zone $\mathrm{C}$, whereas it is longer in zones $\mathrm{A}$ and $\mathrm{D}$.

Previous studies ${ }^{7), 9)}$ indicate that zone A is an old filled-in river; the groundwater level is GL-1 to $-2 \mathrm{~m}$, and the soil is thought to have been liquefied in the filling layer down to GL-5 to $-6 \mathrm{~m}$ below the groundwater level. Zone B is the site of an old gravel mine; the groundwater level here is comparatively deep at GL-2 to $-3 \mathrm{~m}$. Hashimoto et al. ${ }^{9}$ pointed out that the soil below the groundwater

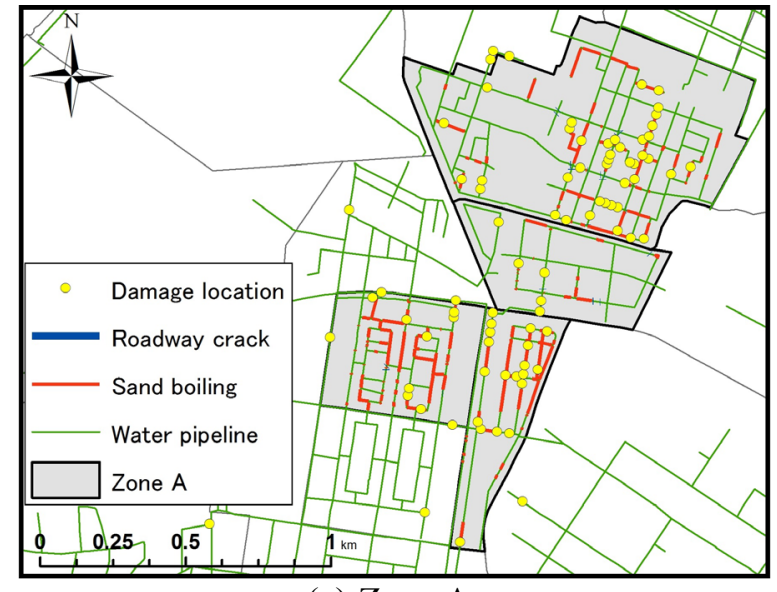

(a) Zone A

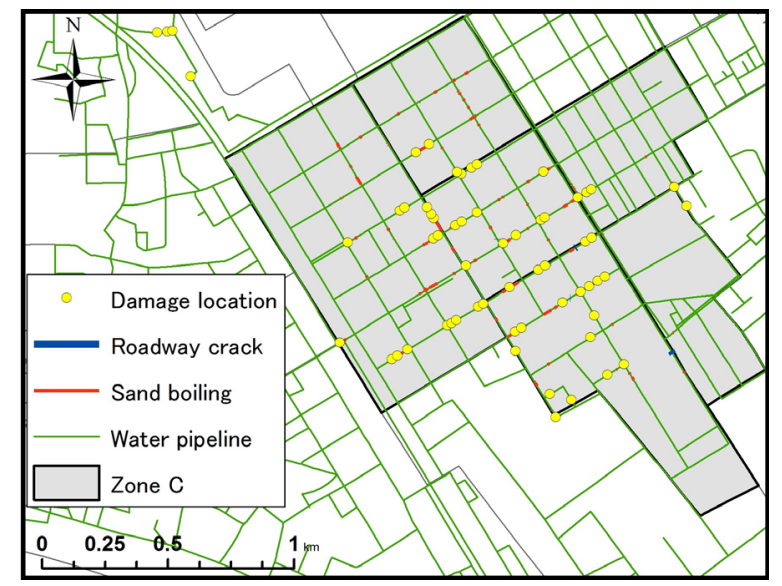

(c) Zone C

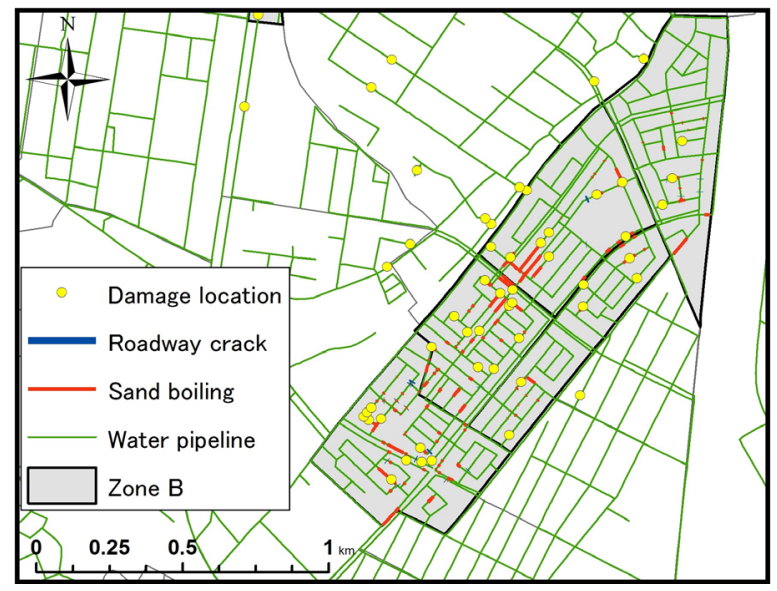

(b) Zone B

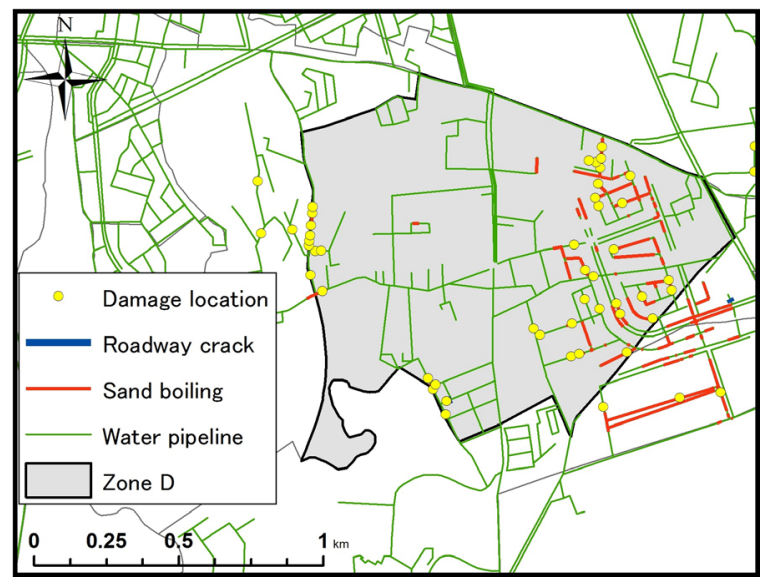

(d) Zone D

Fig. 3 Water-pipeline damage and sand-boiling (SB) in PDCZs 


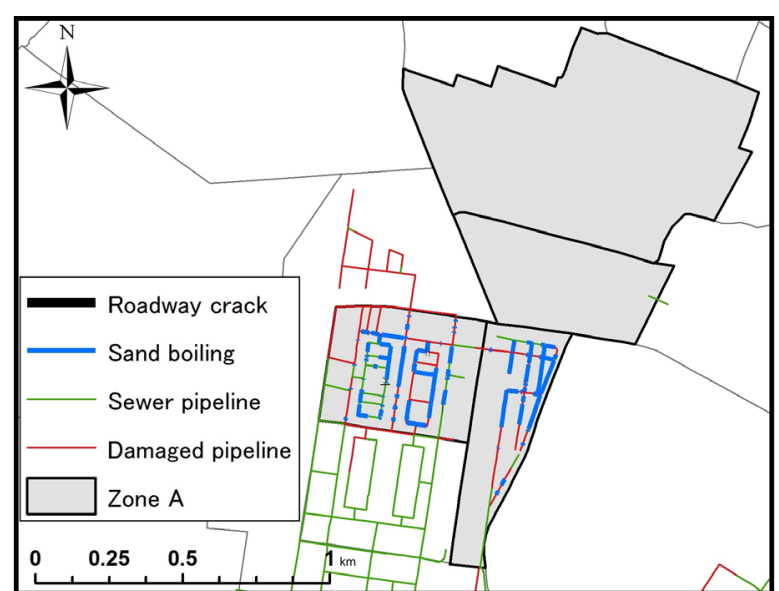

(a) Zone $\mathrm{A}$

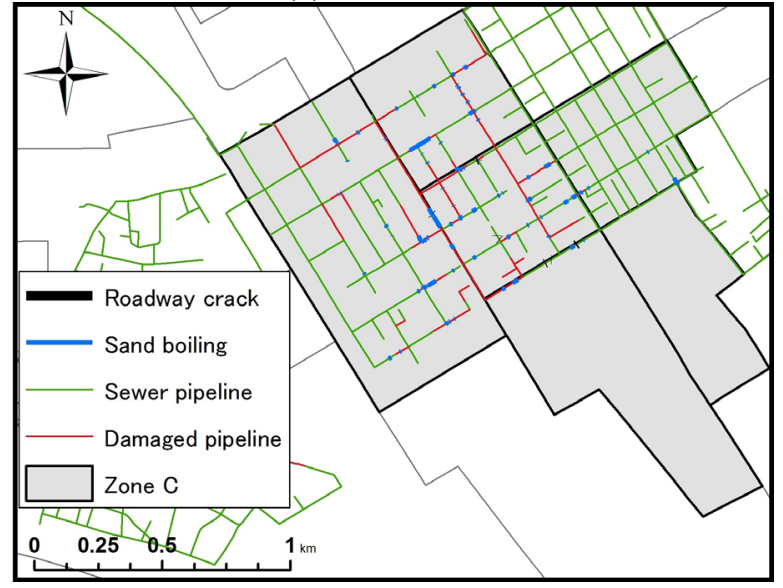

(c) Zone C

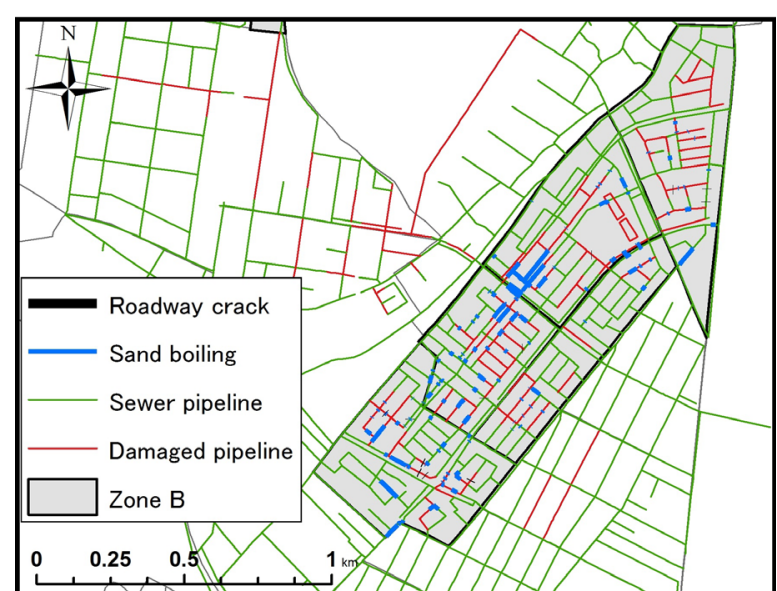

(b) Zone B

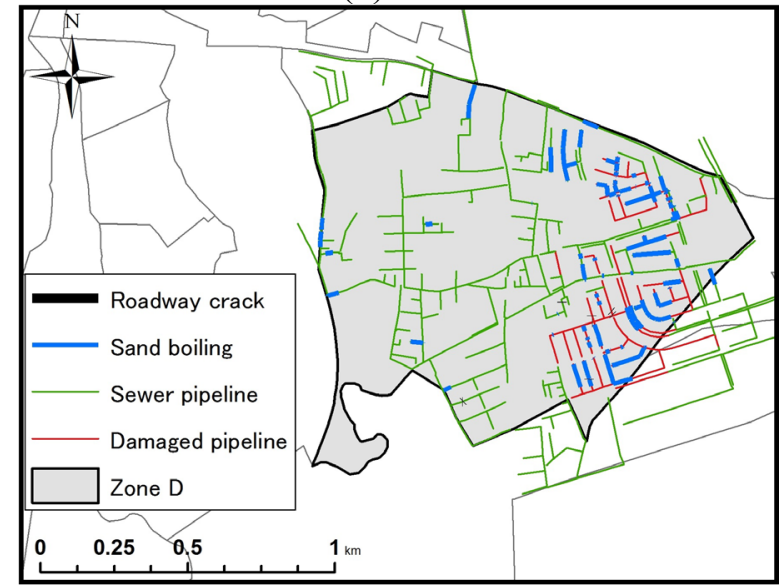

(d) Zone D

Fig. 4 Sewer-pipeline damage and SB in PDCZs

might have been liquefied, but that the amount of SB on the ground surface was relatively small. Although the bore-hole profile in zone D could not be confirmed, zone D is located at the low-altitude between the sand dunes, having the geographical features of a catchment; thus, the groundwater level seems high. In contrast, zone $\mathrm{C}$ is located in low ground between dunes, and has different geographical conditions than those of the other three zones. The region of SB was narrowly distributed in zone $\mathrm{C}$, whereas it was wider in the other three zones.

Despite the geographical differences between zones and the fact that pipes of various diameters had been laid, interviews with officials from the local municipality revealed that the various water and sewer pipelines were all at roughly similar depths of $0.6-1.0 \mathrm{~m}$. The pipeline damage considered in this study depends on the deformation of the ground surface. In cases in which the groundwater level was deep and no SB appeared in the ground surface even though it was liquefied, we consider that the pipeline experienced no adverse effects. Deciding the amount of liquefaction by the extent of SB in the APs may be an effective way to consider the correlation with pipeline damage.

\section{PIPELINE DAMAGE ALONG LIQUEFATION-INDUCED SAND BOILING}

\subsection{Water-pipeline repair rate in sand-boiling areas}

Pipelines in the SB area and road cracks in the PDCZs are hereinafter referred to as pipelines along the SB area. The pipeline repair rate is defined as the number of damage locations in a SB area per length 
of pipeline that it contains. Table 1 lists the statistics of damage data in the SB area in the PDCZs, Of the 146 damage locations in the SB areas, 12 (8.2\% of the total) correspond to parts with road cracks. Therefore, the majority of damaged parts are those associated with SB.

As for the water-pipeline damage modes in the PDCZs, referring to the report by Naba et al., ${ }^{11)}$ all of the 208 damage locations in Kashima City were due to joint separation. In Kamisu City, out of 161 damage locations, 1 was due to pipe cracking, 2 were due to pipe breaking, 1 was due to pipe bending, 1 was due to joint thrusting, and 156 were due to joint separation. Thus, the principal damage mode in the zones can be considered to be joint separation, although information on damage modes is not included in the database in this study.

From Table 1, the number of pipeline-damage locations in the SB areas accounts for $50-84 \%$ of those in the PDCZs. It is thought that more than half of all the liquefaction-induced SB and road cracks became damage factors. The pipe repair rates within the SB area were 10.1 locations $/ \mathrm{km}$ in zone A, 10.8 locations $/ \mathrm{km}$ in zone $\mathrm{B}, 18.2$ locations $/ \mathrm{km}$ in zone $\mathrm{C}$, and 11.2 locations $/ \mathrm{km}$ in zone $\mathrm{D}$. Whereas the previous study ${ }^{6}$ reported that the pipe repair rates in the PDCZs were 10 times higher than those outside the zones in the four cities, the pipe repair rate within the SB areas was over 10 locations $/ \mathrm{km}$, about 10 times higher than that in the PDCZs.

The study of Tsukiji et al. ${ }^{7}$ summarized the pipe repair rate in relation to pipe diameter and pipe material in terms of seismic intensity and peak ground velocity (PGV) in Kamisu City, which cannot be compared directly with this study. The findings were a pipe repair rate of 0.16 locations $/ \mathrm{km}$ (647.9 km, 105 damage locations) in the un-liquefied area and 1.09 locations $/ \mathrm{km}(103.0 \mathrm{~km}, 113$ damage locations) in the liquefied area. Comparing these with Table 1, the un-liquefied area determined by Tsukiji et al. corresponds to an area outside the PDCZs, which were included in their liquefied area since the pipe repair rate of the zones is lower than that of their liquefied area. The SB area with pipeline repair rates of less than 10 locations $/ \mathrm{km}$ appear to be part of their liquefied area.

\subsection{Sewer-pipeline repair rate in sand-boiling areas}

As with water pipelines, we examined the pipeline repair rates in the PDCZs as well as in the SB areas. The sewer-pipeline repair rate is defined as the percentage of damaged pipeline. Table 2 shows the sewer-pipeline repair rates in the PDCZs and in the SB area. The sewer-pipeline repair rate in the PDCZs is as high as $65 \%$ in the southern part of zone A, $25 \%$ in zone B, $24 \%$ in zone C, and $26 \%$ in zone D. In addition, the sewer-pipeline damage rate was $50-73 \%$ in the SB areas in the PDCZs.

The ratio of sewer-pipeline length within the SB area to that in the PDCZs is comparatively low- $44 \%$ in the southern part of zone A, $14 \%$ in zone B, and $12 \%$ in zone C-whereas the ratio of water-pipeline damage locations within the SB area to those in the PDCZs is over 50\%. In other

Table 2 Sewer-pipeline repair rates per unit length

\begin{tabular}{|c|c|c|c|c|}
\hline & & $\begin{array}{l}\text { Damaged } \\
\text { pipeline } \\
(\mathrm{km})\end{array}$ & $\begin{array}{l}\text { Intact } \\
\text { pipeline } \\
(\mathrm{km})\end{array}$ & $\begin{array}{l}\text { Repair } \\
\text { rate } \\
(\mathrm{km} / \mathrm{km})\end{array}$ \\
\hline \multicolumn{2}{|c|}{ Whole area } & 25.18 & 195 & 0.13 \\
\hline \multirow{4}{*}{$\begin{array}{l}\text { Pipeline-d } \\
\text { amage } \\
\text { concentrat } \\
\text { ion zones }\end{array}$} & $\begin{array}{c}\text { Souther } \\
\mathrm{n} \mathrm{A}\end{array}$ & 4.55 & 6.97 & 0.65 \\
\hline & $\mathrm{B}$ & 8.46 & 33.46 & 0.25 \\
\hline & $\mathrm{C}$ & 5.01 & 20.52 & 0.24 \\
\hline & $D$ & 5.39 & 21.08 & 0.26 \\
\hline \multirow{4}{*}{$\begin{array}{l}\text { Sand- } \\
\text { boiling } \\
\text { area }\end{array}$} & $\begin{array}{c}\text { Souther } \\
\mathrm{n} \mathrm{A}\end{array}$ & 1.99 & 2.71 & 0.73 \\
\hline & $B$ & 1.20 & 2.39 & 0.50 \\
\hline & C & 0.62 & 0.99 & 0.63 \\
\hline & $D$ & 1.87 & 3.19 & 0.59 \\
\hline
\end{tabular}

Table 3 Sewer-pipeline repair rates per unit manhole span

\begin{tabular}{|c|c|c|c|c|}
\hline & & $\begin{array}{l}\text { Damaged } \\
\text { pipeline } \\
\text { (Spans) }\end{array}$ & $\begin{array}{l}\text { Intact } \\
\text { pipeline } \\
\text { (Spans }\end{array}$ & $\begin{array}{c}\text { Repair } \\
\text { rate } \\
\text { (Spans/ } \\
\text { spans) }\end{array}$ \\
\hline \multicolumn{2}{|l|}{ Whole area } & 781 & 6,060 & 0.13 \\
\hline \multirow{4}{*}{$\begin{array}{l}\text { Pipeline-d } \\
\text { amage } \\
\text { concentrat } \\
\text { ion zones }\end{array}$} & $\begin{array}{c}\text { Souther } \\
\mathrm{n} A\end{array}$ & 98 & 152 & 0.64 \\
\hline & $B$ & 192 & 767 & 0.25 \\
\hline & C & 109 & 450 & 0.24 \\
\hline & D & 131 & 559 & 0.23 \\
\hline \multirow{4}{*}{$\begin{array}{l}\text { Sand- } \\
\text { boiling } \\
\text { area }\end{array}$} & $\begin{array}{c}\text { Souther } \\
\mathrm{n} \mathrm{A}\end{array}$ & 75 & 110 & 0.68 \\
\hline & $B$ & 77 & 231 & 0.33 \\
\hline & C & 49 & 135 & 0.36 \\
\hline & $\mathrm{D}$ & 76 & 136 & 0.56 \\
\hline
\end{tabular}


words, sewer-pipeline damage is counted even if SB does not appear on the surface ground. This is because the accounting unit is based on damaged length; the damage unit for sewer pipelines is not the repair location but the malfunctioning spans. Thus, even if there is actual damage to only part of a span, the counted damage is regarded as the whole span. It is therefore necessary to recount the sewer-pipeline damage on the basis of damaged spans between manholes. We carried out field investigations in zones A, B, and C at the end of November 2013, and confirmed the manhole locations. As for zone D, because the sewer-pipeline map includes information on manhole location, it was used in place of an investigation. Table 3 gives the sewer-pipeline repair rate per unit manhole span. When a manhole span crosses even part of a SB area, the manhole span is regarded as the one in the SB area. As a result, although the sewer-pipeline repair rate within the SB area decreases somewhat, it is still $33 \%$ or more. In addition, it was confirmed that $40-77 \%$ of damaged manhole spans in the PDCZs were in the SB areas and that the damage occurred at high rates in the SB area as with the water pipelines. The repair rates of zones $\mathrm{B}$ and $\mathrm{C}$ decreased by the unit of manhole span. Because the sections of pipeline associated with SB in these zones are short and numerous, and most of them were not damaged, the number of pipelines in the SB area increases.

In relation to previous studies, Shoji et al. ${ }^{8}$ proposed a formula for estimating the damage to sewer pipelines based on data from Kamisu City and two other cities. The saturated repair rates of the estimation curve indicate $0.247 \mathrm{~km} / \mathrm{km}$ in the liquefaction area and $0.028 \mathrm{~km} / \mathrm{km}$ in the un-liquefied area. The liquefaction area studied by Shoji et al. is roughly the same liquefaction extent as the PDCZs in this study.

\subsection{Relationship between mining site in zone B, pipeline damage, and liquefaction}

By comparing current and old topographical maps, Kuwata and Ikejiri $\left.{ }^{6}\right)$ found that the subsurface in the PDCZs had been artificially modified. Hashimoto et al. ${ }^{9)}$ analyzed the effect of artificial modification on the liquefaction area and pipeline damage by using spatial information on the mining site in zone B from past APs.

Figures 5 and 6 show the former mining site (traced from the figures of Hashimoto et al. ${ }^{9}$ ) and SB areas in zone B. It can be confirmed that the majority of pipelines on a large-scale SB area are located in the former mining site. The repair rates of water and sewer pipelines in the former mining site are listed in Table 4. The span of the sewer pipeline was defined as the span in the former mining site when the pipeline is even partially included in the mining site, as with the definition of the span in the SB area. It is found that $73 \%$ of the $2.49 \mathrm{~km}$ of water pipeline in the SB area in zone B was in the former mining site. The repair rates in the SB areas in the former mining site reached as high as 7.18 locations $/ \mathrm{km}$, which was marginally smaller than those in the SB areas in zone B as a whole. As for the sewer pipelines, the repair rates in the SB areas in the former mining site reached $52 \%$.

\subsection{Damage correlation of water and sewer pipelines in the sand boiling areas}

We examined the spatial correlation between the damage locations of water and sewer pipelines. When both pipelines are installed in the same road in the PDCZs, damage to the sewer pipeline and the presence of SB and road cracks are checked in relation to the locations of damage to the water pipeline. Although there might be cases in which the water and sewer pipelines are installed in different sides of the road, we consider them to be adjacent if they are on the same road. Table 5 is an arrangement of damage to the water and sewer pipelines in the four zones of the PDCZs. The damage locations of water pipelines that are not adjacent with sewer pipelines are more than $50 \%$ because there are no pipelines installed in the northern part of zone A.

In zone $\mathrm{A}$, all the sewer pipelines adjacent to water-pipeline damage locations were damaged regardless of the presence of SB. In the other zones, the percentage of damaged sewer pipelines adjacent to water-pipeline damage locations in the SB areas corresponds to $70 \%$ or more. In contrast, for damage locations of water pipelines outside the SB areas, only around $60 \%$ of sewer pipelines were damaged. However, this percentage increases for pipelines that are in SB areas. 


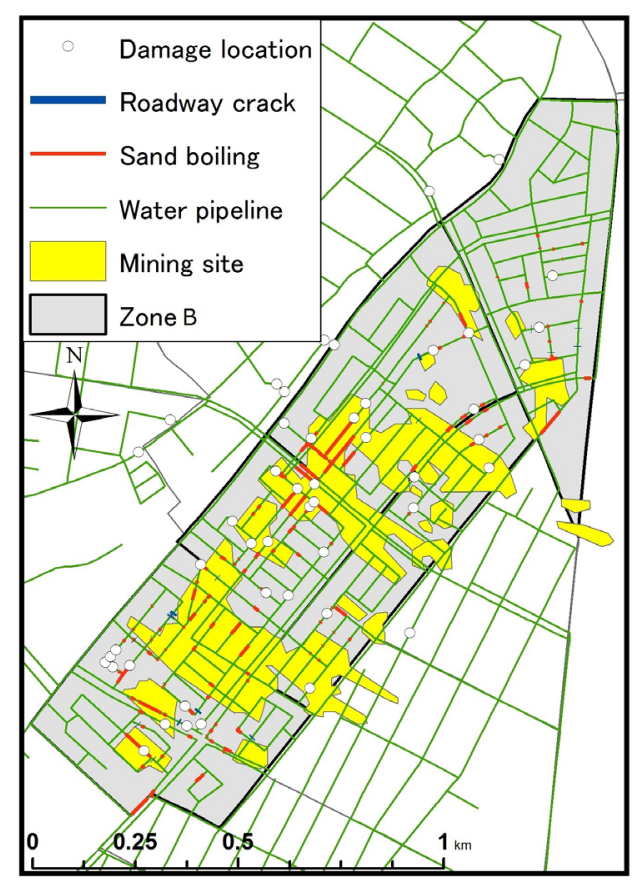

Fig. $5 \mathrm{SB}$ over the former mining site: water pipeline

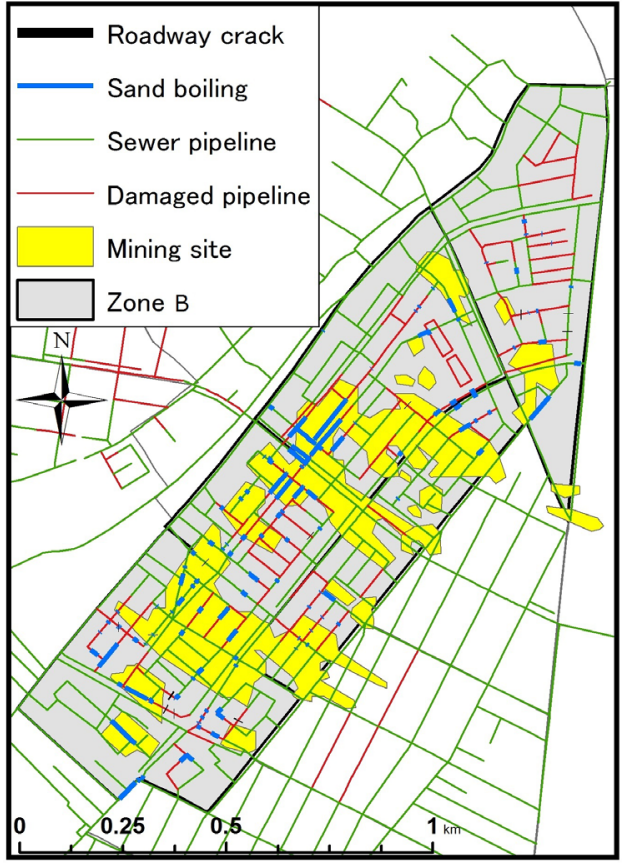

Fig. $6 \mathrm{SB}$ over the former mining site: sewer pipeline

Table 4 Damage to water and sewer pipelines in the former mining site

\begin{tabular}{l||c|c|c||c|c|c}
\hline & $\begin{array}{c}\text { Damage } \\
\text { locations } \\
\text { of water } \\
\text { pipeline } \\
\text { (locations) }\end{array}$ & $\begin{array}{c}\text { Pipeline } \\
(\mathrm{km})\end{array}$ & $\begin{array}{c}\text { Repair rate of } \\
\text { water } \\
\text { pipeline } \\
\text { (locations } \\
/ \mathrm{km})\end{array}$ & $\begin{array}{c}\text { Damage } \\
\text { locations of } \\
\text { sewer } \\
\text { pipeline } \\
\text { (spans) }\end{array}$ & $\begin{array}{c}\text { Pipeline } \\
\text { (spans) }\end{array}$ & $\begin{array}{c}\text { Repair rate of } \\
\text { sewer } \\
\text { pipeline }\end{array}$ \\
\hline Zone B & 42 & 28.7 & 1.39 & 197 & 767 & 0.25 \\
\hline Sand-boiling in zone B & 27 & 2.49 & 10.84 & 77 & 231 & 0.33 \\
\hline Former mining site & 17 & 9.71 & 1.75 & 81 & 289 & 0.28 \\
\hline Sand-boiling in mining site & 13 & 1.81 & 7.18 & 35 & 67 & 0.52 \\
\hline
\end{tabular}

\section{SPATIAL RELATIONSHIP BETWEEN LIQUEFACTION SAND BOILING AND PIPELINE DAMAGE}

\subsection{Spatial relationship between liquefaction sand boiling and water-pipeline damage}

We consider the spatial relationship between water-pipeline damage locations and SB areas. Figure 6 shows the relationship between pipeline length in the SB areas and the number of cases in which there was one or more damage locations on these pipeline lengths in the PDCZs. In the target zones, the pipeline on the SB area covers comparatively short ranges of $15 \mathrm{~m}$ or less. As the length of SB-coved pipeline increases, the number of cases decreases. In only a few cases does the SB-covered pipeline length exceed $100 \mathrm{~m}$. As the SB-covered pipeline length increases, the number of cases in which pipeline damage occurs at least once decreases, while the incidence of damage cases per pipeline cases approaches $100 \%$. The diameters of the water pipelines in the target zones are $100 \mathrm{~mm}$ or less, and the unit length of these straight pipes is 4 or $5 \mathrm{~m}$. In other words, if liquefaction occurs with SB over a length of two or three pipes, the incidence of pipeline damage can be said to become about $20 \%$. 
Table 5 Damage correlation of water and sewer pipelines in the target zones

\begin{tabular}{|c|c|c|c|c|c|c|c|}
\hline Zone & $\begin{array}{l}\text { Damage status of } \\
\text { sewer pipeline (SP) }\end{array}$ & $\begin{array}{l}\text { Damage to } \\
\text { WP (with } \\
\text { sand-boiling) } \\
\text { (locations) }\end{array}$ & $\begin{array}{l}\text { Rate of } \\
\text { adjacent } \\
\text { SP }\end{array}$ & $\begin{array}{l}\text { Damage to } \\
\text { WP (without } \\
\text { sand-boiling) } \\
\text { (locations) }\end{array}$ & $\begin{array}{l}\text { Rate of } \\
\text { adjacent } \\
\text { SP }\end{array}$ & $\begin{array}{c}\text { Damage to } \\
\text { WP } \\
\text { (locations) }\end{array}$ & $\begin{array}{l}\text { Rate of } \\
\text { adjacent } \\
\text { SP }\end{array}$ \\
\hline \multirow{4}{*}{ A } & Damage to SP & $14:$ & $100.0 \%$ & 7 & $100.0 \%$ & 21 & $100.0 \%$ \\
\hline & No damage to SP & $0:$ & $0.0 \%$ & 0 & $0.0 \%$ & 0 & $0.0 \%$ \\
\hline & No adjacent SP & $49 \vdots$ & - & 5 & - & 54 & - \\
\hline & Subtotal & 63 & & 12 & & 75 & \\
\hline \multirow{4}{*}{ B } & Damage to SP & 16 & $59.3 \%$ & 9 & $69.2 \%$ & 25 & $62.5 \%$ \\
\hline & No damage to SP & $11:$ & $40.7 \%$ & 4 & $30.8 \%$ & 15 & $37.5 \%$ \\
\hline & No adjacent SP & 0 & - & 0 & - & 0 & - \\
\hline & Subtotal & 27 & & 13 & & 40 & \\
\hline \multirow{4}{*}{$\mathrm{C}$} & Damage to SP & $12 \vdots$ & $66.7 \%$ & 9 & $52.9 \%$ & 21 & $60.0 \%$ \\
\hline & No damage to SP & 6 & $33.3 \%$ & 8 & $47.1 \%$ & 14 & $40.0 \%$ \\
\hline & No adjacent SP & 9 & - & 10 & - & 19 & - \\
\hline & Subtotal & 27 & & 27 & & 54 & \\
\hline \multirow{4}{*}{$\mathrm{D}$} & Damage to SP & 20 & $71.4 \%$ & 2 & $22.2 \%$ & 22 & $59.5 \%$ \\
\hline & No damage to SP & $8:$ & $28.6 \%$ & 7 & $77.8 \%$ & 15 & $40.5 \%$ \\
\hline & No adjacent SP & $4:$ & - & 1 & - & 5 & - \\
\hline & Subtotal & 32 & & 10 & & 42 & \\
\hline \multirow{4}{*}{ Total } & Damage to SP & 62 & $71.2 \%$ & 27 & $58.7 \%$ & 89 & $66.9 \%$ \\
\hline & No damage to SP & 25 & $28.8 \%$ & 19 & $41.3 \%$ & 44 & $33.1 \%$ \\
\hline & No adjacent SP & 62 & - & 16 & - & 78 & - \\
\hline & Subtotal & 149 & & 62 & & 211 & \\
\hline
\end{tabular}

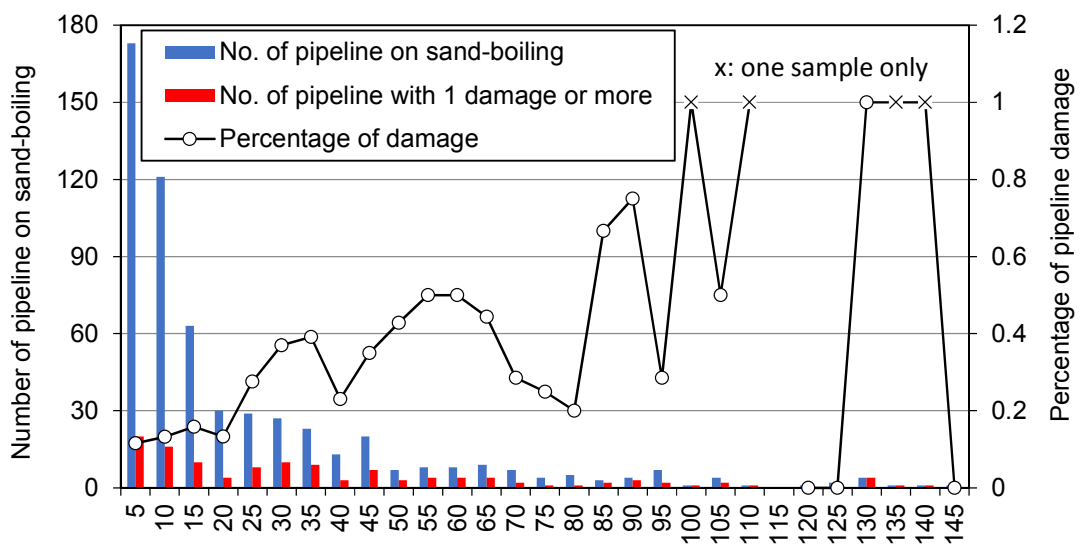

Length of pipeline on sand-boiling $(<\mathrm{m})$

Fig. 6 Percentage of pipeline damage based on the length of pipeline on the SB

Next, the relationship between the magnitude of SB area and the locations of water-pipeline damage is considered. The SB length $\mathrm{L}$ of the pipeline and the distance between the damage location and the edge of the SB area are shown in Figure 7 (b). Figure 7 (a) shows the distribution of damage location according to the SB length of the pipeline. In cases in which there are two or more damage locations on one pipeline, each location is measured. The horizontal axis of Figure 7 (a) is normalized by the length of the pipeline. This means that if it is near zero, the damage location is near the boundary of the SB area; if it is near 0.5, the damage location is at the center of the SB area. When the 
SB length of the pipeline is less than $10 \mathrm{~m}$, the damage is concentrated at the center of the SB area. In cases in which the length is $10 \mathrm{~m}$ or more, the damage occurs in the center or in the vicinity of the boundary of the SB area. Taking into account the length of straight pipe, when the SB covers the range of two pipes or less, the liquefaction-induced ground deformation is concentrated in the center of the SB area. When the SB covers three pipes or more, a deformation gap forms between the liquefied and un-liquefied ground, and the pipeline damage near the boundary of the SB area becomes more than that in the center.

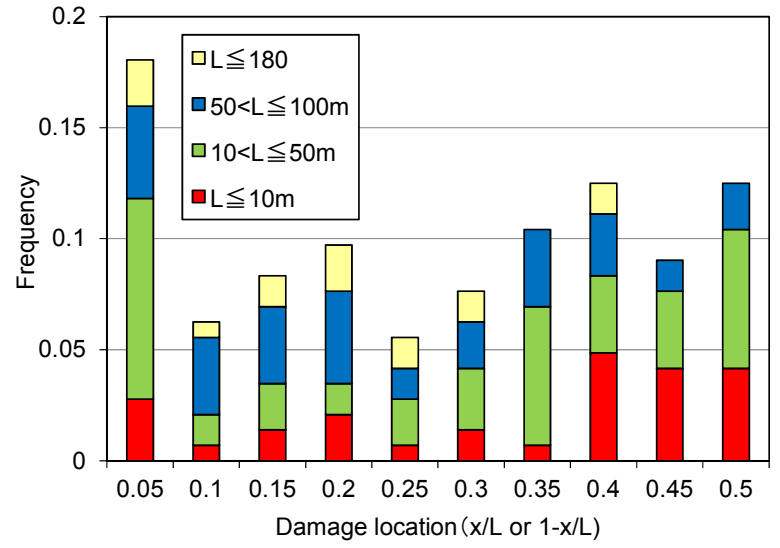

(a) Frequency of damage location in the SB area

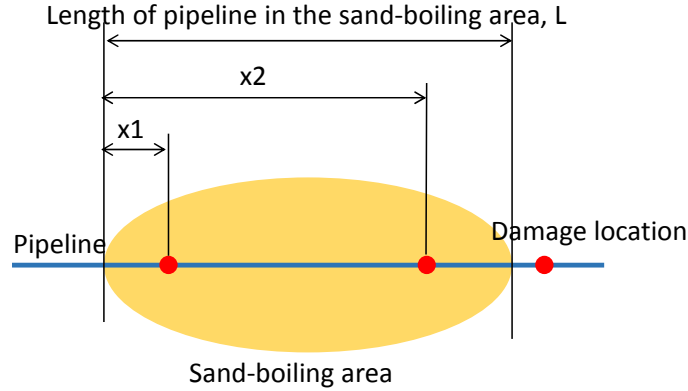

(b) Image of measurement of damage location

Fig. 7 Location of pipeline damage in SB

\subsection{Spatial relationship between liquefaction sand-boiling and sewer-pipeline damage}

The spatial relationship between the locations of damage to sewer pipelines and the SB areas is considered. First of all, the magnitude of SB area in which damage to sewer pipelines occurred and the presence of SB around manholes are checked from the APs. When SB area is observed over two or more manhole spans, sewer-pipeline damage is defined as the damage in two or more manhole spans. Because the state of sewer-pipeline damage is defined not as a damage location but as a damaged span, unlike a water pipeline, the relationship between SB and damage location cannot be clarified. Thus, the relationship is analyzed instead based on the ratio of SB-covered length to manhole spans. Figure 8 shows the percentage of SB area according to the damaged manhole spans. The number of cases decreases as the damaged manhole span increases. When SB occurs within a damaged manhole span, the SB area is less than $30 \%$ in the most cases. In only a few cases is the SB area between $30 \%$ and $80 \%$. However, cases of more than $80 \%$ SB increase. This tendency of SB is similar to that of a damaged manhole with two spans. As for three spans, cases with more than $80 \%$ SB increase, as do those in which the damaged-manhole span exceeds $100 \mathrm{~m}$. It is confirmed that there are two cases: local SB over one manhole span or large-scale SB over multiple manhole spans.

Liquefaction damage to sewer pipelines can be considered in one of two modes: liquefaction around a manhole or liquefaction around a pipeline. The presence of liquefaction around a manhole is checked by the damaged manhole spans. Table 6 shows the presence of SB around a manhole in each damaged manhole span according to the rate of SB area. Because the number of cases differed by SB area, the SB area is classified into cases of less than $30 \%$, less than $80 \%$, and more. When there is only one damaged manhole span and the SB area is less than $30 \%$, cases of SB around a manhole are comparatively few: 11 among 42 cases (approximately 26\%). When the area becomes more than 30\%, the cases increase to around $40 \%$. When there are more than two damaged manhole spans, SB generated around the manholes regardless of the magnitude of the SB area. In the case of one damaged span, the SB is relatively small, whereas in the case of more than two damaged spans, SB often generated around the manhole at the center of the spans. Out of 165 damaged manhole spans, SB around the manhole was confirmed at 104 spans (63\%); the rest was SB around the pipeline. 


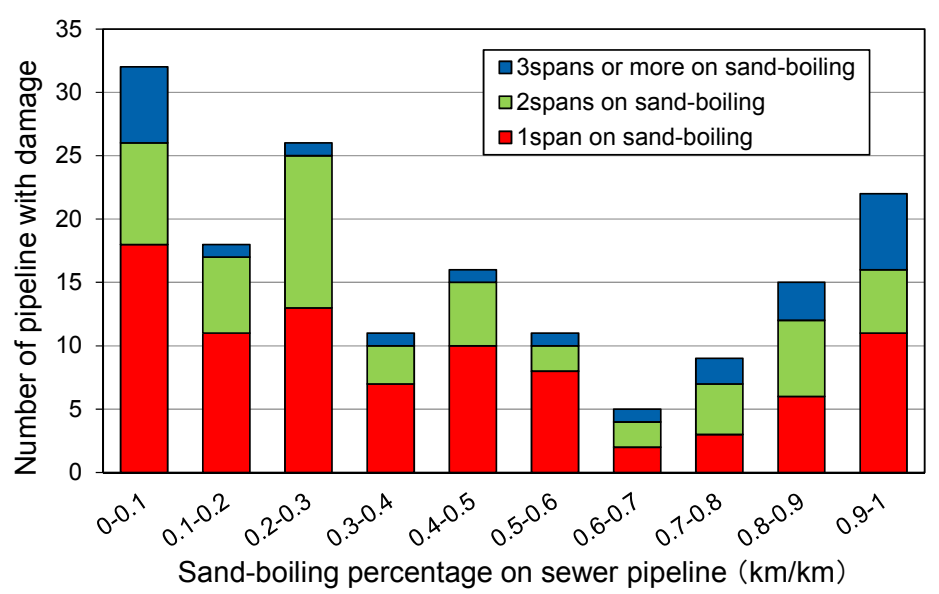

Fig. 8 Percentage of SB in the damaged manhole spans

Table 6 Damaged sewer pipelines by the magnitude of SB

\begin{tabular}{|c|c|c|c|c|}
\hline \multirow{2}{*}{$\begin{array}{l}\text { Manhole spans } \\
\text { with damage }\end{array}$} & \multirow{2}{*}{$\begin{array}{l}\text { Percentage of sand } \\
\text { boiling, P (\%) }\end{array}$} & \multirow{2}{*}{$\begin{array}{l}\text { Incidents of } \\
\text { damage } \\
\text { (No.) }\end{array}$} & \multicolumn{2}{|c|}{$\begin{array}{c}\text { Sand boiling around } \\
\text { manhole }\end{array}$} \\
\hline & & & (No.) & $(\%)$ \\
\hline \multirow{3}{*}{1 span } & $0<\mathrm{P}<30$ & 42 & 11 & $26 \%$ \\
\hline & $30 \leqq P<80$ & 30 & 11 & $37 \%$ \\
\hline & $80 \leqq P \leqq 100$ & 17 & 7 & $41 \%$ \\
\hline \multirow{3}{*}{2 spans } & $0<P<30$ & 26 & 25 & $96 \%$ \\
\hline & $30 \leqq P<80$ & 16 & 16 & $100 \%$ \\
\hline & $80 \leqq P \leqq 100$ & 11 & 11 & $100 \%$ \\
\hline \multirow{3}{*}{3 spans or more } & $0<P<30$ & 8 & 8 & $100 \%$ \\
\hline & $30 \leqq P<80$ & 6 & 6 & $100 \%$ \\
\hline & $80 \leqq P \leqq 100$ & 9 & 9 & $100 \%$ \\
\hline \multirow{3}{*}{ Subtotal } & $0<\mathrm{P}<30$ & 76 & 44 & $58 \%$ \\
\hline & $30 \leqq P<80$ & 52 & 33 & $63 \%$ \\
\hline & $80 \leqq P \leqq 100$ & 37 & 27 & $73 \%$ \\
\hline
\end{tabular}

\section{CONCLUSIONS}

In this study, the area of liquefaction-induced SB in the PDCZs in the Kashima region was specified from aerial photography, and the spatial relationship between the water and sewer pipelines on the SB area and these damage locations was clarified. The following conclusions can be drawn from this study.

- The water-pipeline repair rate in the liquefaction SB area exceeded 10 locations $/ \mathrm{km}$, which is approximately 10 times the repair rate in the PDCZs in the Kashima region.

- The incidence of water-pipeline damage within the SB area was $50-84 \%$ of those in the PDCZs, of which more than half were caused by SB or road cracks due to liquefaction.

- The rate of sewer-pipeline damage within the SB area was $33 \%$ or more with respect to the manhole spans. In addition, $40-77 \%$ of the damaged sewer pipelines in the PDCZs (in units of manhole span) were in the SB area.

- In PDCZ B, roughly $73 \%$ of the SB-covered pipeline was at the former mining site on the basis of pipeline length. The pipeline damage rate in the SB area at the former mining site was 7.18 locations $/ \mathrm{km}$ for water pipelines and $52 \%$ for sewer pipelines.

- When a water pipeline was damaged in the SB area, the adjacent sewer pipeline was also damaged 
in $70 \%$ or more of cases on average. In contrast, for pipelines not in the SB area, the percentage decreased to around $60 \%$. In other words, the percentage in the SB area was higher.

- If there was $10 \mathrm{~m}$ or less of water pipeline in the SB area, it was damaged in the center of the area. As the pipeline became longer, the damage was located nearer to the boundary of the SB area.

- Out of 165 damaged manhole spans, SB around a manhole was confirmed at 104 spans (63\%); the rest was SB around the pipeline.

\section{ACKNOWLEDGMENT}

The authors would like to express their sincere thanks to Kamisu City and Kashima City in Ibaraki Prefecture for providing the data on earthquake damage to water service pipelines and drainage pipelines that was used in this study.

\section{REFERENCES}

1) Water Service Section, Health Service Bureau, The Ministry of Health, Labour and Welfare: Final report on damage to water service facilities during the East Japan earthquake and disaster, 2013. (in Japanese)

2) Technical Committee for Earthquake and Tsunami Measures to Drainage System: Summary on the damage to drainage facilities and the earthquake and tsunami measures in East Japan earthquake and disaster, 2012. (in Japanese)

3) Hamada, M. and Akioka, Y.: Ground strain induced lateral flow and its damage to buried pipe, Proceedings of the JSCE Earthquake Engineering Symposium, Vol. 24, pp.1353-1356, 1997. (in Japanese)

4) Hamada, M., Yasuda, S., Isoya, R. and Emoto, K.: Study on liquefaction induced permanent ground displacements, Association for the Development of Earthquake Prediction, 1986.

5) Toida, R. and Yamazaki, F.: Analysis of liquefaction damage in Urayasu City in the 2011 Tohoku, Japan Earthquake using aerial photographs, Journal of Institute of Social Safety Science, No. 18, pp.221-228, 2012. (in Japanese)

6) Kuwata, Y. and Ikejiri, D.: Liquefaction-induced pipeline damage concentration and landform and land use changes in the Kashima region, Journal of Japan Association for Earthquake Engineering, Vol.12, pp. 4_249-4_262, 2012. (in Japanese)

7) Tsukiji, T., Terajima, R., Shoji, G. and Nagata, S.: Damage assessment on water supply systems in the 2011 off the Pacific coast of Tohoku earthquake-case study for the data at Itako City and Kamisu City, Journal of Japan Society of Civil Engineers, Ser. A1 (Structural Engineering \& Earthquake Engineering (SE/EE)), Vol. 69, No. 4, p. I_260-I_279, 2013. (in Japanese)

8) Shoji, G., Terajima, R. and Nagata, S.: Development of damage functions on sewer buried pipelines subjected to an extreme ground motion from damage assessment based on the data in recent earthquake, Journal of Japan Society of Civil Engineers, Ser. A1 (Structural Engineering \& Earthquake Engineering (SE/EE)), Vol. 70, No. 4, p. I_921-I_946, 2014. (in Japanese)

9) Hashimoto, T., Yasuda, S. and Shoji, G.: Analysis on liquefaction damages of houses, sewer pipes and roads distributed in mined areas at Fukashiba and Hiraizumi in Kamisu City in the 2011 off the Pacific coast of Tohoku earthquake, Journal of Japan Society of Civil Engineers, Ser. A1 (Structural Engineering \& Earthquake Engineering (SE/EE)), Vol. 71, No. 4, p. I_376-I_386, 2015. (in Japanese)

10) Kokusai Kogyo Co., Ltd.: Aerophotograph orthodata, 2011.

11) Naba, S., Tsukiji, T., Shoji, G. and Nagata, S.: Damage assessment on water supply system and sewerage system at the 2011 off the Pacific coast of Tohoku earthquake-case study for the data at Ibaraki and Chiba Prefectures, Journal of Japan Society of Civil Engineers, Ser. A1 (Structural Engineering \& Earthquake Engineering (SE/EE)), Vol. 68, No. 4, p. I_1194-I_1209, 2012. (in Japanese) 